\title{
Yao syndrome: A potential role and association of vasoactive intestinal peptide with NOD2
}

Brianne Navetta-Modrov, Berhane Ghebrehiwet, Qingping Yao*

Division of Rheumatology, Allergy and Immunology, Department of Medicine, Stony Brook University, Renaissance School of Medicine, Stony Brook, NY, USA

Abstract

Received October 10, 2020 accepted January 17, 2021

Nucleotide-binding oligomerization domain containing protein 2 (NOD2) is a cytosolic receptor. Both NOD2 and vasoactive intestinal peptide (VIP) are critical in regulation of immune and inflammatory response. Yao syndrome (YAOS, OMIM 617321) is an autoinflammatory disease associated with specified NOD2 mutations. Herein, we report a well-studied case of YAOS masquerading as mast cell disorder and neuroendocrine tumors to support the involvement of VIP in YAOS. For the first time, this case study suggests a potential relationship between NOD2 and VIP. This could provide a novel avenue for mechanistic study of NOD2-associated disease.

Keywords

NOD2 • NOD2-associated autoinflammatory disease $\cdot$ rash $・$ vasoactive intestinal peptide $・$ Yao syndrome

\section{Introduction}

Nucleotide-binding oligomerization domain-containing protein 2 (NOD2) is a cytosolic receptor and plays a critical role in defense against microbial infections, regulation of the inflammatory process, and maintenance of immune homeostasis..$^{[1]}$ NOD2 gene mutations are linked to Crohn's disease, Blau syndrome, and Yao syndrome (YAOS, OMIM 617321). ${ }^{[1,2]}$ YAOS, formerly termed NOD2-associated autoinflammatory disease, is characterized by periodic fever, dermatitis, arthritis, and swelling of the distal extremities, as well as gastrointestinal and sicca-like symptoms. ${ }^{[2]}$

Vasoactive intestinal peptide (VIP) is synthesized by various cells to inhibit the inflammatory and immune response. ${ }^{[3]}$ Herein, we report a well-studied case of YAOS masquerading as mast cell disorder and neuroendocrine tumors to suggest the involvement of VIP in YAOS and its potential association with NOD2.

\section{Case Presentation}

A 39-year-old Caucasian female was essentially healthy until 3 months after the uneventful delivery of her daughter 1 year ago, when she presented with intermittent bouts of cutaneous flushing and diarrhea. Skin flushing and rash occurred on her face, neck, upper chest, and upper arms. The skin flushing was intermittent and related to hot/ high heat, and her rash was nonpruritic and described by a dermatologist as erythematous macules with a sharply demarcated border (Figure 1). Her diarrhea was episodic and non-bloody, loose to watery. There was abdominal bloating without abdominal pain. Her facial flushing and diarrhea started each morning and occurred up to 10 times daily. Her diarrhea did not wake her up in the middle of the night or have any relation to food intake. The patient reported near syncopal symptoms feeling dizzy and lightheaded, which lasted 2-3 h with each episode. Also, she endorsed low-grade fever, weight loss of 10 pounds, mild pain in her fingers/ankles with minimal swelling, and dry eyes/mouth.

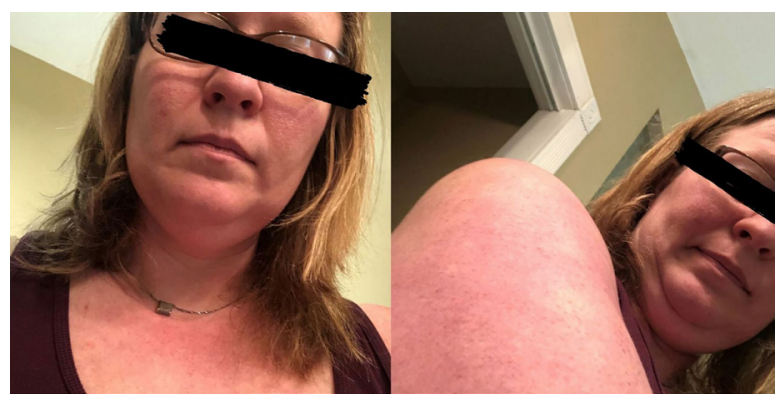

Figure 1. Rash: cutaneous flushing on the face and neck, patchy erythema on upper chest and macules 
Table 1. Laboratory, imaging, and pathology data

\begin{tabular}{|c|c|c|}
\hline Category & Item & Result \\
\hline I. Routine & Erythrocyte sedimentation rate, C-reactive protein, immunoglobulins (lgG, $\operatorname{lgA}, \lg M)(\mathrm{mg} / \mathrm{dL}), \mathrm{UA}$ & Normal \\
\hline II. Allergic & $\begin{array}{l}\text { Environmental allergens (lgE), immunoglobulin E (IU/mL) } \\
\text { Serum tryptase }(\mu \mathrm{g} / \mathrm{L}) \text {, 24-h urine } \mathrm{N} \text {-methyl histamine }(\mathrm{mcg} / \mathrm{g} \mathrm{Cr}) \text {, 2, 3-dinor } 11 \text { beta prostaglandin } \\
\text { F2alpha }(\mathrm{pg} / \mathrm{mg} \mathrm{Cr}) \text { leukotriene } \mathrm{E} 4 \mathrm{pg} / \mathrm{mg} \mathrm{Cr}) \text {; galactose } 1-3 \text { alpha galactose }(\mathrm{kU} / \mathrm{L}) \text {, } \\
\text { CKIT D816V mutation (PCR) }\end{array}$ & $\begin{array}{l}\text { Normal or negative except } \\
\text { N-methylhistamine: } 243(30-200)\end{array}$ \\
\hline III. Endocrine & $\begin{array}{l}\text { Serum gastrin }(\mathrm{pg} / \mathrm{mL}) \text {, calcitonin }(\mathrm{pg} / \mathrm{mL}) \text {, vitamin } \mathrm{D}(\mathrm{ng} / \mathrm{mL}) \text {, metanephrine, 24-h urine } 5 \text { HIAA } \\
\text { VIP (serial measurements by radioimmunoassay) }(\mathrm{pg} / \mathrm{mL})\end{array}$ & $\begin{array}{l}\text { Normal except } \\
\text { gastrin: } 156(0-115) \\
\text { calcitonin: } 5.6(0-5) \\
\text { vitamin D:11 (30-100) } \\
\text { VIP: } 91.7,66.9,41.4,123.2,90.0(0-58.5)\end{array}$ \\
\hline IV. Imaging & $\begin{array}{l}\text { Chest radiograph, CT of the chest, abdomen and pelvis with contrast, Dotatate PET/CT, CT of the } \\
\text { pancreas, upper endoscopy with EUS, brain MRI/MRA, tilt table, EEG, echocardiogram, Holter } \\
\text { monitor }\end{array}$ & Negative except small umbilical hernia \\
\hline $\begin{array}{l}\text { V. Endoscopy and } \\
\text { pathology }\end{array}$ & $\begin{array}{l}\text { Esophagogastroduodenoscopy/colonoscopy/capsule endoscopy } \\
\text { Skin biopsy } \\
\text { Bone marrow biopsy with flow cytometry } \\
\text { Peripheral blood flow cytometry }\end{array}$ & $\begin{array}{l}\text { Normal except mild chronic gastritis } \\
\text { Superficial perivascular inflammatory } \\
\text { cell infiltrate (predominantly } \\
\text { lymphocytes), negative DIF } \\
\text { Normal } \\
\text { Normal }\end{array}$ \\
\hline VI. Genetic testing & NOD2 mutation (whole-gene sequencing) & $\begin{array}{l}\text { NOD2: c. } 2798+158 \mathrm{C}>\mathrm{T}(\mathrm{IVS} 8+158) \text {, } \\
\text { homozygous } \\
\text { NOD2: c.2104C }>\mathrm{T}(\mathrm{R} 702 \mathrm{~W}) \\
\text { heterozygous }\end{array}$ \\
\hline
\end{tabular}

Abbreviations: CT, computed tomography; DIF, direct immunofluorescence; EEG, electroencephalogram; EUS, endoscopic ultrasound; HIAA, hydroxyindoleacetic acid; MRI, magnetic resonance imaging; MRA, magnetic resonance angiography; NOD2, nucleotide-binding oligomerization domain-containing protein 2; PCR, polymerase chain reaction; PET, positron emission tomography; UA, uric acid; VIP, vasoactive intestinal peptide.

The patient reported several episodes of throat closing or spasmatic feeling, palpitations, and constricted breathing during disease flares with normal oxygen saturation. As a result, she visited emergency rooms/clinics frequently, and she was hospitalized several times and underwent extensive multidisciplinary workup in several medical centers. Her home medications included fludrocortisone, cetirizine, loratadine, cromolyn, famotidine, montelukast, and epinephrine autoinjector. She received four doses of omalizumab with minimal symptomatic improvement. She had a history of mild asthma since childhood with no known drug allergy and had a family history of YAOS in her sister. The patient's relevant laboratory, imaging, and pathologic study results are summarized in Table 1.

\section{Discussion}

YAOS is a systemic inflammatory disease and can mimic autoimmune, allergic, and other disorders. ${ }^{[4]}$ Patients often undergo a multidisciplinary workup for relevant disorders including systemic mastocytosis and neuroendocrine tumors as in our case. During the diagnostic process, our patient has been found to have elevated VIP levels in serial measurements of plasma by radioimmunoassay. In the end, the patient was diagnosed with YAOS based on the diagnostic criteria, i.e., characteristic clinical phenotype and genotype (NOD2 variants, IVS8+158 and R702W), and exclusion of relevant diseases. ${ }^{[2]}$ After the failure to respond to sulfasalazine, the patient received canakinumab $150 \mathrm{mg}$ subcutaneously every 2 months for two doses, with significant improvement of her symptoms and physical functional ability, because the drug is effective for the disease. ${ }^{[5]}$

The finding of VIP elevation in our patient with YAOS is intriguing. VIP secretions are typified by Vipomas, in which VIP acts via binding to VPAC1 receptors leading to hypersecretions and cutaneous flushing as in our case..$^{[3,6,7]}$ Our case raises an important question. Would VIP have any association with NOD2? To our knowledge, there have been no studies of their relationship in the literature. Our case study is the first to show a potential relationship since VIP elevation has been observed in the context of YAOS with the presence of NOD2 mutations as a major feature. All YAOS patients carry NOD2 mutations; nearly all patients carry NOD2 IVS8+158 variant and up to $30 \%$ of patients have concurrent NOD2 R702W as in our case. ${ }^{[8]}$ NOD2 is primarily present in monocytes, macrophages, dendritic cells, and the intestinal endothelium. It detects a bacterial cell wall component, muramyl dipeptide, 
and causes NOD2 signal transduction cascades, which in turn activates mitogen-activated kinases (MAPKs) and NF-kB, eventually leading to proinflammatory cytokine secretions. ${ }^{[1]}$ While the pathogenesis of YAOS is still elusive, our prior study of the NOD2 pathway has shown that NOD2 transcriptional levels and its signal pathway are aberrant in YAOS, with overproduction of proinflammatory cytokines like IL-6. ${ }^{[9]}$ VIP is a natural anti-inflammatory agent able to

Conflict of Interest

The authors declare no conflicts of interest.

Funding

No support in the forms of grants or industrial support.

Informed Consent

Informed consents have been obtained.

References

[1] Yao Q. Nucleotide-Binding Oligomerization Domain Containing 2: Structure, Function, and Diseases. Semin Arthritis Rheum. 2013;43:125-130.

[2] Yao Q, Shen B. A Systematic Analysis of Treatment and Outcomes of NOD2-Associated Autoinflammatory Disease. Am J Med. 2017;130(3):365 e13-365 e18.

[3] Ganea D, Hooper KM, Kong W. The Neuropeptide Vasoactive Intestinal Peptide: Direct Effects on Immune Cells and Involvement in Inflammatory and Autoimmune Diseases. Acta Physiologica. 2015;213:442-452.

[4] Yao Q, Su LC, Tomecki KJ, et al. Dermatitis as A Characteristic Phenotype of A New Autoinflammatory Disease Associated with NOD2 Mutations. J Am Acad Dermatol. 2013;68:624631.

[5] Yao Q. Research Letter: Effectiveness of Canakinumab for the Treatment of Yao Syndrome Patients. J Am Acad Dermatol. 2019 Sep 18. pii: S0190-9622(19)32757-4. doi: 10.1016/j. jaad.2019.09.020. [Epub ahead of print].

[6] Ito T, Igarashi $H$, Jensen RT. Pancreatic Neuroendocrine inhibit proinflammatory cytokines such as TNFa, IL-6, and IL-12. In addition, it is also known to inhibit the P38 MAPK pathway and NF-KB. ${ }^{[10]}$ Taken together, VIP may participate in the NOD2 activation pathway and contributes to YAOS. The most important implication of this novel finding is the potential association between NOD2 and VIP. Further study of their interrelationship would provide a new avenue for mechanistic study of relevant diseases.
Tumors: Clinical Features, Diagnosis and Medical Treatment: Advances. Best Pract Res Clin Gastroenterol. 2012;26:737753.

[7] Bennett LA, Johnson JM, Stephens DP, et al. Evidence for A Role for Vasoactive Intestinal Peptide in Active Vasodilatation in the Cutaneous Vasculature of Humans. J Physiol. 2003;552:223-232.

[8] Yao Q, Shen M, McDonald C, et al. NOD2-Associated Autoinflammatory Disease: A Large Cohort Study. Rheumatology (Oxford). 2015;54:1904-1912.

[9] McDonald C, Shen M, Johnson EE, et al. Alterations in Nucleotide-Binding Oligomerization Domain-2 Expression, Pathway Activation, and Cytokine Production in Yao Syndrome. Autoimmunity. 2018;51:53-61.

[10] Chedid P, Boussetta T, Dang PM, et al. Vasoactive Intestinal Peptide Dampens Formyl-Peptide-Induced ROS Production and Inflammation by Targeting a MAPK-p47(phox) Phosphorylation Pathway in Monocytes. Mucosal Immunol. 2017;10:332-340. 